\title{
Impact of pyrrolidine-bispyrrole DNA minor groove binding agents and chirality on global proteomic profile in Escherichia Coli
}

\author{
Ya-ting Yang ${ }^{1 *}$, Chun-Yu Lin ${ }^{1}$, Jingyueh Jeng ${ }^{2 *}$ and Chi-Wi Ong ${ }^{1}$
}

\begin{abstract}
Background: There is great interest in the design of small molecules that selectively target minor grooves of duplex DNA for controlling specific gene expression implicated in a disease. The design of chiral small molecules for rational drug design has attracted increasing attention due to the chirality of DNA. Yet, there is limited research on the chirality effect of minor groove binders on DNA interaction, especially at the protein expression level. This paper is an attempt to illustrate that DNA binding affinity might not provide a full picture on the biological activities. Drug interacting at the genomic level can be translated to the proteomic level. Here we have illustrated that although the chiral bispyrrole-pyrrolidine-oligoamides, PySSPy and PyRSPy, showed low binding affinity to DNA, their influence at the proteomic level is significant. More importantly, the chirality also plays a role. Two-dimensional proteomic profile to identify the differentially expressed protein in Escherichia coli DH5a (E coli DH5a) were investigated.
\end{abstract}

Results: $E$ coli DH5a incubated with the chiral PySSPy and PyRSPy, diastereomeric at the pyrrolidine ring, showed differential expression of eighteen proteins as observed through two dimensional proteomic profiling. These eighteen proteins identified by MALDI_TOF/TOF MS include antioxidant defense, DNA protection, protein synthesis, chaperone, and stress response proteins. No statistically significant toxicity was observed at the tested drug concentrations as measured via MTT assay.

Conclusion: The current results showed that the chiral PySSPy and PyRSPy impact on the proteomic profiling of E coli DH5a, implicating the importance of drug chirality on biological activities at the molecular level.

Keywords: Escherichia coli, Pyrrolidine-bispyrroles, Proteomics, Chirality, Matrix-assisted laser desorption/ionization (time of flight), Protein up- and down-regulation

\section{Background}

Genomics has dramatically altered the way of drug discovery, and as such, small molecules with the ability to sequence-selectively recognize and discriminate between DNA have become increasingly important for the control of specific processes involved in gene expression implicated in diseases [1-5]. The minor grooves of DNA have been shown to play important roles in the regulation of gene expression and are normally unoccupied [6], hence they are considered a susceptible site of attack

\footnotetext{
* Correspondence: tinayang101@gmail.com; jyjeng@hotmail.com 'Department of Chemistry, National Sun Yat-sen University, No. 70, Lienhai Rd., Kaohsiung 80424, Taiwan

${ }^{2}$ Department of Biotechnology, Chia Nan University of Pharmacy \& Science, No. 60, Sec. 1, Erren Rd., Rende Dist., Tainan City 71710, Taiwan
}

by small molecules less than $1000 \mathrm{kDa}$ [7]. Consequently much interest has been concentrated in the design of small molecules that selectively target minor grooves of duplex DNA in order to control specific gene expression implicated in a disease [1]. There is limited research investigating the chirality effect of minor groove binders on DNA interaction. The dimerization of two $\mathrm{N}$-methylpyrrole oligopeptides through the chiral linker methanodiazocin scaffold has shown that the $(4 R, 9 R)$ form is better suited for interaction with calf thymus DNA than the (4S,9S)-form [8]. In addition, Herman et al. (1998) has shown that the enantiomer derived from two distamycin A-derived polyamides linked by either (R)-2,4-diaminobutyric acid showed enhanced binding affinity towards DNA when compared to the

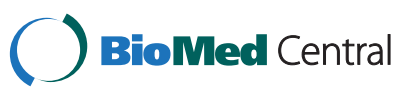


(S)-2,4-diaminobutyric acid-enantiomer [9]. Our laboratory has recently designed and synthesized two distamycin A-derived diastereoisomers, depicted as PySSPy and PyRSPy [10]. These two diastereoisomers have their middle pyrrole group replaced with a pyrrolidine group and the terminal amide group removed (Figure 1).

Genome research has led to medical advances against diseases [11,12]. However, human complexity cannot be entirely explained by its genomics, but by the way their gene products interact. To further complicate the matter, genome is a static process while proteome is a dynamic process. In other words, one gene can encode for a number of proteins. While most drugs target proteins, disease profiling is at present dominated by DNA microarrays [13-15]. As such, there may not be a good correlation between gene expression and protein expression in most disease processes, and treatments can be manifested at the protein level. Thus, it is believed that gene-based expression analysis alone is inadequate for drug discovery.

In the past, protein expression has been analyzed through mRNA studies. However, it was later shown that mRNA content does not correlate with protein content as mRNA is not always translated into protein [16-19]. On the other hand, proteomics is a systematic analysis that measures protein expression directly and not via gene expression, yet serving as a complementary approach to genomics. 2D gel electrophoresis is still the most useful way to separate proteins in complex samples in proteomics profiling and allows simultaneous analyses of vast amount of protein data, making it suitable for comparative analysis of a reference cell protein profile with a profile after drug treatment in the search of new drug or drug target. At present there are minimal researches on the consequences of DNA minor groove binding agents on the proteomic profile in cells.
Escherichia coli (E. coli) are one of the best-characterized prokaryotes. Since the completion of the E. coli genomesequencing project [20], this organism has been studied on the genome wide scale in terms of its transcriptome, proteome, interactome, metabolome, and physiome [21-25]. The uses of proteomics technologies on $E$ coli have generated unprecedentedly large amounts of proteome data for $E$ coli [25-27]. This extensive $E$ coli proteome database has therefore made $E$ coli an ideal model organism for a largescale comparison of protein expression levels under particular chemical and physical stresses [26]. Our initiative is to examine whether proteomics is a more realistic end point for drug action, and at the same time the chirality effects on protein expression. To achieve this goal, we have synthesized chiral compounds PySSPy and PyRSPy and performed the proteomic profiling analyses on an E. Coli DH5 $\alpha$ strain by performing 2D gel electrophoresis coupled with mass spectrophotometry to determine the expressional changes on different proteins. This method allows us to carry out a simultaneous search on a vast number of proteins that may have expressional changes. We have also examined the protein expressional changes of $E$. Coli $D H 5 \alpha$ in response to tripyrrole-oligoamide (3A). This compound is also a distamycin A-derived compound, which retains the middle pyrrole group that is achiral. The proteomic profiling of the achiral 3A is examined to confirm the influence of chirality. Although there are numerous differentially expressed proteins, in this work we have identified the most significant eighteen proteins that have either been up- or down-regulated, and the chirality of the compound was found to play an important role.

\section{Results}

Susceptibility of $E$ coli DH5a to bispyrrole-pyrrolidines

To examine the susceptibility of Escherichia coli DH5 $\alpha$ (E coli $\mathrm{DH} 5 \alpha$ ) towards PySSPy, E coli DH5 $\alpha$ treated with
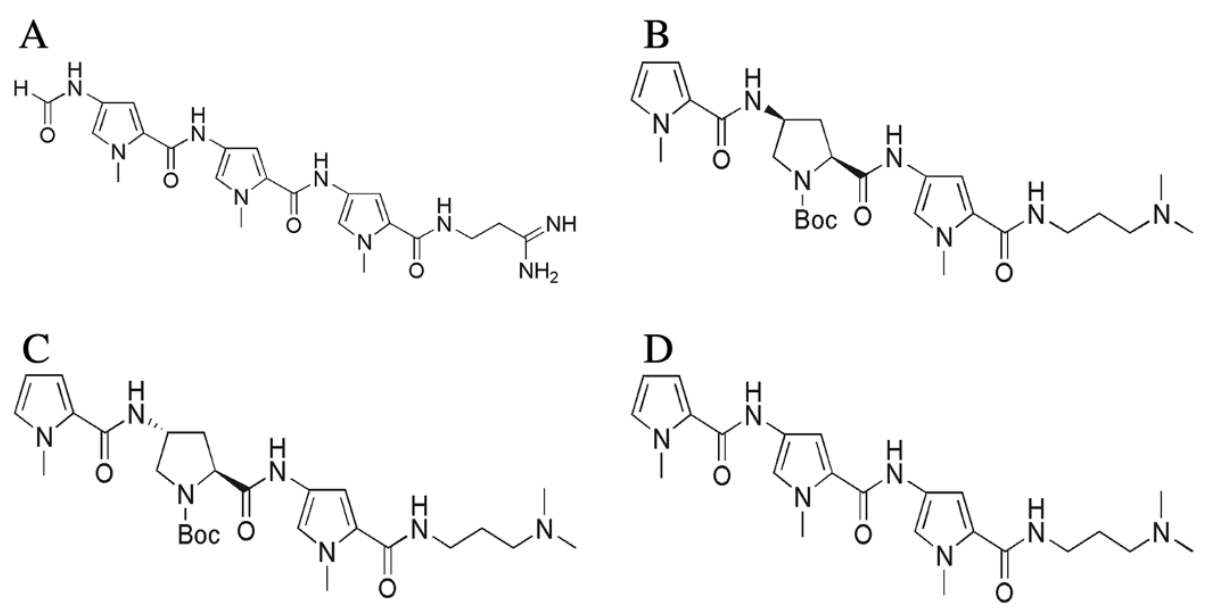

Figure 1 Chemical structures of distamycin A, PySSPy, PyRSPy and 3A. (A) Distamycin A. (B) PySSPy (C) PyRSPy (D) Tripyrrole-oligoamide $(3 \mathrm{~A})$, a distamycin-A derived achiral compound retaining the middle pyrrole group. 
variable PySSPy concentrations were examined for their cell growth via $\mathrm{OD}_{600}$ analyses (Additional file 1). The growth curve of the non-treated cells exhibited a 6-hour lag phase, followed by a 6-hour exponential phase and subsequently a stationery phase. At 9-hr incubation, E coli DH5 $\alpha$ treated with 100, 150, 200 and $300 \mu \mathrm{M}$ PySSPy showed approximately $8(\mathrm{p}<0.01)$, $10(\mathrm{p}<0.001), 12(\mathrm{p}<0.001)$ and 20\% $(\mathrm{p}<0.001)$ decreases in cell density, respectively. However, the growth curves of the PySSPy treated cells eventually reached the same plateaus as that of the control cells. The results indicate the non-toxic nature of PySSPy on E coli DH5 $\alpha$. A concentration of $300 \mu \mathrm{M}$ was subsequently chosen for the rest of the study to maximize the possible effects of PySSPy on $E$ coli DH5 $\alpha$ proteome.

The cytotoxicity of PySSPy, PyRSPy and 3A was subsequently compared (Figure 2). Exposure of $E$ coli DH5 $\alpha$ to either $300 \mu \mathrm{M}$ PySSPy or PyRSPy resulted in approximately $20 \%$ decreases in cell viability at 9-hr time period $(\mathrm{p}<0.001)$, after which the cell growth curves became comparable to that of the control ( $p>$ 0.05). Exposure of E coli DH5 $\alpha$ to $300 \mu \mathrm{M} 3 \mathrm{~A}$ resulted in no statistically significant decreases in cell density over time. Overall, these results suggest that PySSPy and PyRSPy have limited cytotoxicity effects on E coli DH5a even at a high concentration of $300 \mu \mathrm{M}$.

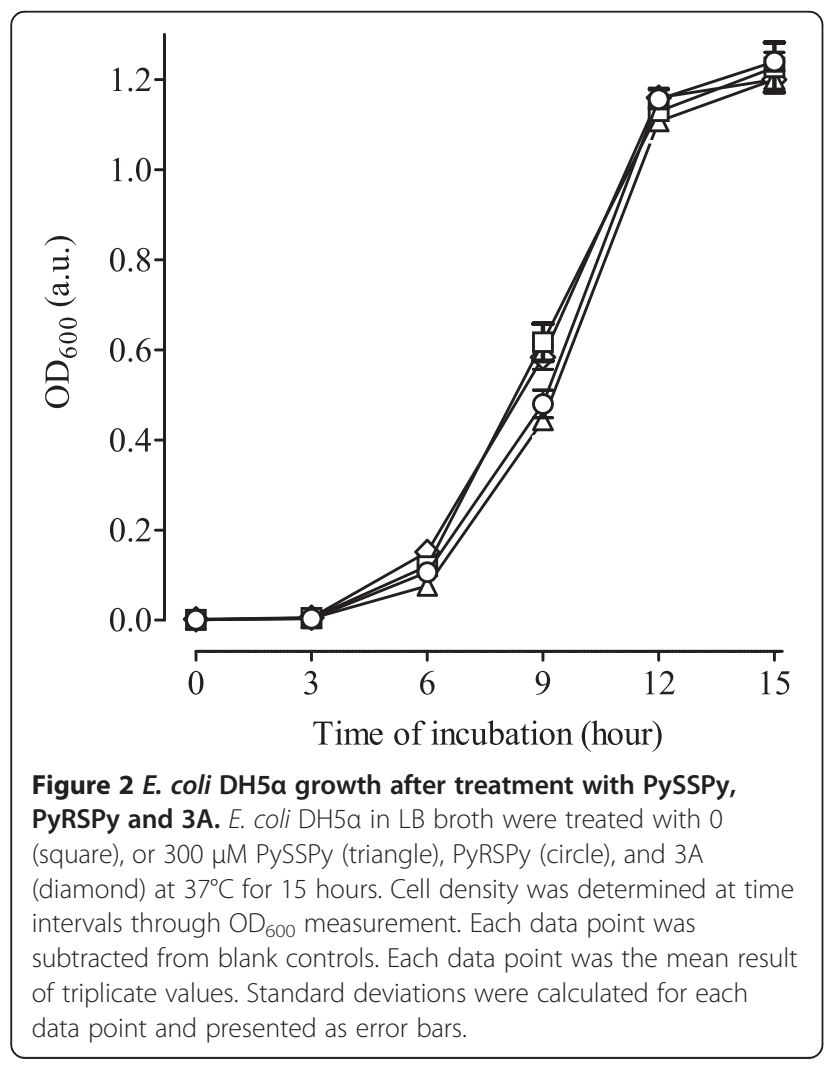

\section{Proteomic analyses}

The lack of cytotoxicity observed in PySSPy- and PyRSPyand 3A-treated E. coli DH5 $\alpha$ allows the further study of their influence at the molecular level associated with the global protein expression. Differential protein expression in E. coli DH5 $\alpha$ cells following exposure to $300 \mu \mathrm{M}$ PySSPy, PyRSPy and 3A for 9 hours were examined using a comparative proteomic analysis. Protein spots resulted from the PySSPy-, PyRSPy- and 3A-treated 2-DE gels were compared with the corresponding protein spots from the control gel. The proteomic profiles of total proteins from the control and treated E. coli DH5 $\alpha$ from three independent experiments were shown in Additional files 2, 3,4 to 5 .

The representative proteomic profile of total proteins from the control E. coli $\mathrm{DH} 5 \alpha$ showed that proteins were widely distributed across the $\mathrm{pI}$ range (4-7) between the molecular weight 16 and $143 \mathrm{kDa}$ (Figure 3). After comparison with the control, some protein spots from the PySSPy-, PyRSPy- and 3A-treated gels with significant expressional change were excised from the gels (Figure 4) and identified by MALDI-TOF mass spectrometry using peptide mass fingerprint searches (Table 1). Eighteen protein spots in total were successfully identified with significant scores and high sequence coverage. The abundance of the remaining protein spots were either too low to be detected

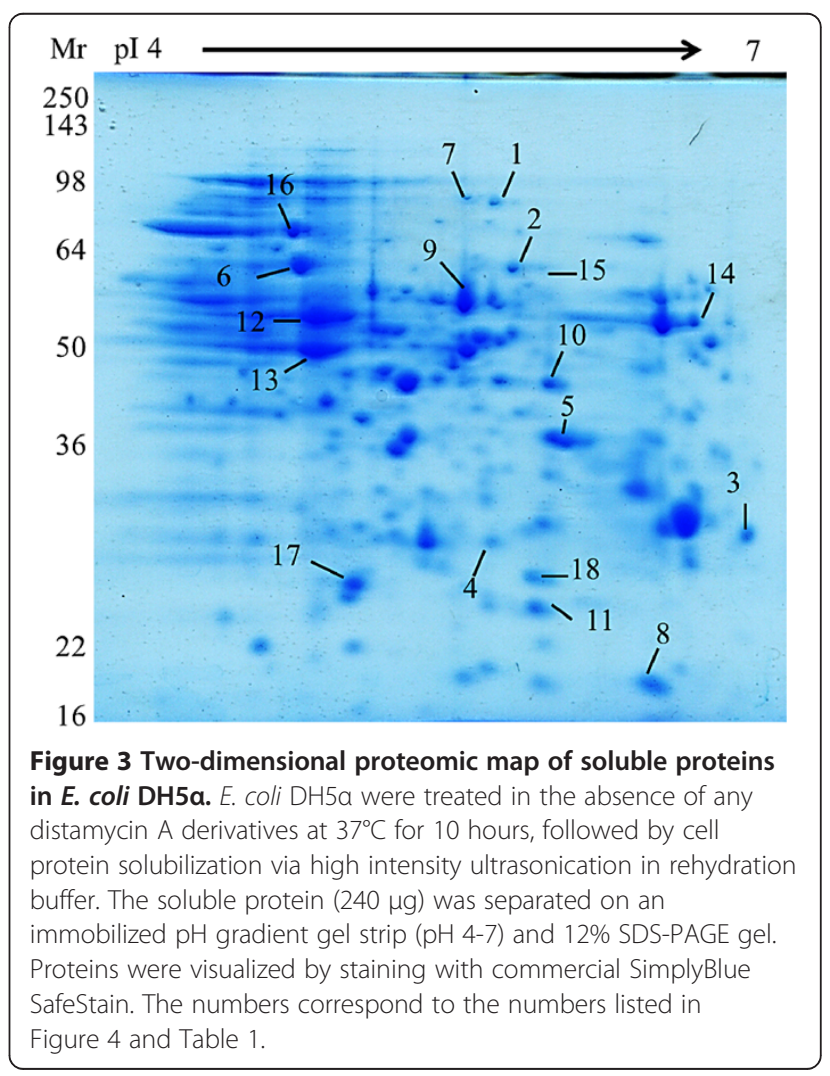




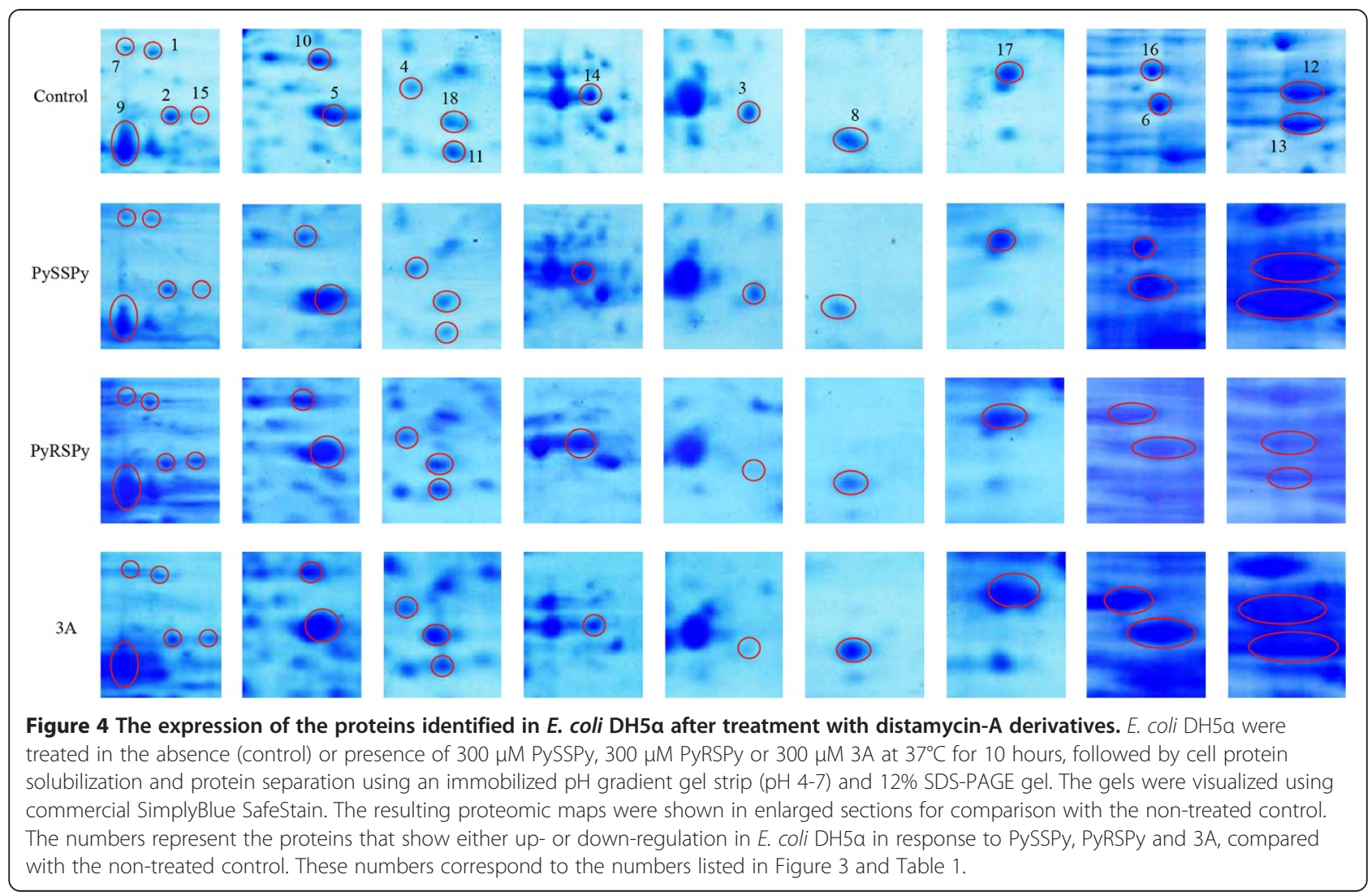

or the scores did not reach statistical significance. The data suggests that PySSPy. PyRSPy and 3A at a non-cytotoxic concentration can still induce alteration in protein expression.

The 18 proteins in $E$ coli DH5 $\alpha$ identified that showed differential expression in response to either PySSPy or PyRSPy or both are listed in Table 1. Both PySSPy and PyRSPy induced significant down-regulation of serine hydroxymethyltransferase, glycerol kinase, succinate dehydrogenase iron-sulfur subunit, NADP-dependent malic enzyme and DNA protection during starvation protein. Malate dehydrogenase, 2-dehydro-3-deoxy-Dgluconate 5 dehydrogenase and $60 \mathrm{kDa}$ chaperonin 1 were significantly up-regulated by both PySSPy and PyRSPy. Interestingly, selective proteins were differentially expressed in response to either PySSPy or PyRSPy alone. PySSPy alone significantly down-regulated phosphoenolpyruvate carboxykinase, aminomethyltransferase and superoxide dismutase [Fe], and up-regulated ATP synthase subunit beta and elongation factor $\mathrm{Tu}$ 1. PyRSPy alone significantly up-regulated tryptophanase, bifunctional purine biosynthesis protein purH, chaperone protein dnaK, alkyl hydroperoxide reductase subunit $\mathrm{C}$ and KHG/KDPG aldolase. In addition, the control 3A alone did not induce differential protein expression. The results suggest these two diastereoisomers differing only in their chiral center show protein selectivity, whereas the chiral $3 \mathrm{~A}$ is less selective in protein expression regulation.

The proteins identified can be classified into several groups using the UniProtKB database and the KEGG database based on their molecular functions, including transferases, oxidoreductases, lyases, hydrolases, elongation factor, and chaperone. These proteins are involved in metabolism (serine hydroxymethyltransferase, NADP-dependent malic enzyme, glycerol kinase, phosphoenolpyruvate carboxykinase, aminomethyltransferase, 2-dehydro-3 deoxy-D-gluconate 5-dehydrogenase, succinate dehydrogenase iron-sulfur subunit, ATP synthase subunit beta, bifunctional purine biosynthesis protein purH, tryptophanase, KHG/KDPG aldolase and malate dehydrogenase), antioxidant defense (superoxide dismutase [Fe], DNA protection during starvation protein and alkyl hydroperoxide reductase subunit $\mathrm{C}$ ), protein synthesis (elongation factor $\mathrm{Tu} 1$ ), DNA replication (chaperone protein dnaK) and stress response $(60 \mathrm{kDa}$ chaperonin $1)$, rather than taking part in a wide variety of biological processes.

\section{Discussion}

Selective and cytostatic anticancer agents may not express their biological activities through cell death or tumor 
Table 1 Identification of differentially expressed proteins of E coli DH5a treated with PySSPy, PyRSPy and 3A

\begin{tabular}{|c|c|c|c|c|c|c|c|c|}
\hline \multirow{2}{*}{ No. } & \multirow{2}{*}{$\begin{array}{c}\text { ICBI } \\
\text { accession No. }\end{array}$} & \multirow{2}{*}{ Protein identified } & \multirow{2}{*}{$\begin{array}{c}\text { Calculated } \\
\mathrm{pl} / \mathrm{MW} \\
(\mathrm{kDa})\end{array}$} & \multirow{2}{*}{$\begin{array}{l}\text { Matched } \\
\text { (Measured) } \\
\text { peptide }\end{array}$} & \multirow{2}{*}{$\begin{array}{c}\text { Sequence } \\
\text { coverage } \\
(\%)\end{array}$} & \multicolumn{3}{|c|}{ Relative intensities $^{a}$} \\
\hline & & & & & & PySSPy & PyRSPy & $3 A$ \\
\hline 1 & GLYA_EC024 & $\begin{array}{l}\text { Serine hydroxymethyl- } \\
\text { transferase }\end{array}$ & $6.03 / 94$ & $9(22)$ & 29 & $-25 \pm 04$ & $-2.1 \pm 0.2$ & $-1.4 \pm 0.1$ \\
\hline 2 & IR3Z2_ECOUT & Glycerol kinase & $5.97 / 60$ & $15(30)$ & 33 & $-2.3 \pm 0.4$ & $-1.6 \pm 0.05$ & $-1.7 \pm 0.1$ \\
\hline 3 & DHSB_ECQU & $\begin{array}{l}\text { Succinate dehydrogenase } \\
\text { iron-sulfur subunit }\end{array}$ & 6.327 & $10(21)$ & 47 & $-2.4 \pm 0.1$ & $-3.5 \pm 0.3$ & $-3.4 \pm 0.1$ \\
\hline 4 & KDUD_ECOLI & $\begin{array}{l}\text { 2-dehydro-3-deoxy-D- } \\
\text { gluconate 5-dehyrixenase }\end{array}$ & $5.24 / 27$ & $8(18)$ & 40 & $+1.7 \pm 0.1$ & $+2.0 \pm 0.2$ & $+1.9 \pm 0.2$ \\
\hline 5 & IVEH_ECO24 & Malate dehydrogenase & $5.61 / 32$ & $11(22)$ & 49 & $+2.3 \pm 0.2$ & $+3.1 \pm 0.05$ & $+1.9 \pm 0.06$ \\
\hline 6 & CH6O1_ECOK1 & 60 kDa chaperonin 1 & 4.85157 & $10(26)$ & 33 & $+2.4 \pm 0.1$ & $+2.5 \pm 0.2$ & $+3.1 \pm 0.4$ \\
\hline 7 & MAO2_ECOLI & $\begin{array}{l}\text { NADP-dependent malic } \\
\text { enzyme }\end{array}$ & 5,3494 & $11(13)$ & 14 & $-21 \pm 0.5$ & $-2.1 \pm 0.3$ & NS \\
\hline 8 & DPS_EC024 & $\begin{array}{l}\text { DNA protection during } \\
\text { starvation protein }\end{array}$ & $5.72 / 19$ & $9(1)$ & 58 & $-2.3 \pm 0.1$ & $-2.8 \pm 0.6$ & NS \\
\hline 9 & PCKA_EC024 & $\begin{array}{l}\text { Phosphoenolpyruvate } \\
\text { carboxykinase }\end{array}$ & $5.46 / 60$ & $14(27)$ & 35 & $-24 \pm 0.2$ & NS & NS \\
\hline 10 & GCST_EC024 & Aminomethyltransferase & $5.36 / 40$ & $9(17)$ & 35 & $-2.1 \pm 0.3$ & NS & NS \\
\hline 11 & SODF_ECO57 & superoxide dismutase $[\mathrm{Fe}]$ & $5.58 / 53$ & $15(16)$ & 37 & NS & $+1.9 \pm 0.009$ & NS \\
\hline 12 & ATPB_EC024 & ATP synthase subunit beta & 4.9150 & $16(50)$ & 50 & $+3.0 \pm 0.2$ & NS & $+2.6 \pm 0.2$ \\
\hline 13 & EFTIJ1_EC024 & Elongation factor Tu 1 & 53143 & $17(44)$ & 53 & $+3.3 \pm 0.2$ & NS & $+3.1 \pm 0.1$ \\
\hline 14 & TNAA_EC024 & Tryptophanase & $5.88 / 53$ & $15(16)$ & 37 & NS & $+1.9 \pm 0.009$ & NS \\
\hline 15 & PUR9_ECO5S & $\begin{array}{l}\text { Bifunctional purine } \\
\text { biosynthesis protein purH }\end{array}$ & $5.53 / 58$ & $11(14)$ & 31 & NS & $+1.3 \pm 0.2$ & $+1.6 \pm 0.06$ \\
\hline 16 & DNAK_ECO24 & Chaperone protein dnak & $4.83 / 69$ & $16(28)$ & 28 & NS & $+3.0 \pm 0.1$ & $+2.1 \pm 0.2$ \\
\hline 17 & AHPC_ECO57 & $\begin{array}{l}\text { Alkyl hydroperoxide } \\
\text { reductase subunit C }\end{array}$ & $5.0 / 21$ & $6(11)$ & 43 & NS & $+2.6 \pm 0.3$ & $+2.5 \pm 0.4$ \\
\hline 18 & ALKH_ECO57 & KHG/KDPG aldolase & $5.57 / 22$ & $7(20)$ & 46 & NS & $+1.8 \pm 0.2$ & $+2.1 \pm 0.3$ \\
\hline
\end{tabular}

a "-" indicates down-regulation and " + " indicates up-regulation. The numerical values indicate the relative intensities of protein spots of interest in comparison with the corresponding control proteins, and they are presented as mean \pm standard deviations of at least 2 independent proteomic gels. "NS" indicates the intensity changes are statistically non-significant in comparison to the corresponding control proteins.

shrinking, but on the tuning of the biochemical activities of protein to effect survival. The synthesized PySSPy, PyRSPy and 3A showed weak binding to calf thymus DNA [10] and low cytotoxicity (Figure 2). Even so, the current study using 2- dimensional gel electrophoresis coupled with mass spectrophotometry [28-31] has allow us to identified 18 responsive proteins involved in different biological processes to be up- or down regulated by these compounds (Figure 4 and Table 1). This illustrate that proteomics may be a more important to fully expressed the interaction of drugs at the cellular level. Here, PySSPy and PyRSPy were shown to selectively affect several proteins, and these results are promising.

The achiral compound 3A was found to be less selective in influencing particular protein expression. Its impacts on protein expression seemed to be more random as compared to those of PySSPy and PyRSPy, implying the importance of chirality in regulating selective protein expression. The 18 proteins with altered expression level in
PySSPy- and PyRSPy-treated E coli DH5 $\alpha$ can be categorized into a broad range of different functional classes, including metabolism, cellular defenses, DNA replication, stress responses, and protein synthesis. The wide range of different proteins involved suggested that PySSPy and PyRSPy can induce profound biological responses in $E$ coli $\mathrm{DH} 5 \alpha$.

Among the 18 proteins, PySSPy alone has shown to down-regulation of 3 proteins and up regulation of 2 proteins, whereas PyRSPy alone up-regulated 5 proteins (Table 1). This result suggests that PySSPy and PyRSPy that differ only in configuration of one stereogenic center can alter the expression of selective genes. This indicates that these chiral compounds may exert differential cellular effects. The present preliminary data illustrate the importance of coupling proteomics studies with genomic studies to obtain a clearer picture for the biological activities of drugs. Of interest is the down-regulation of phosphoenolpyruvate carboxykinase by PySSPy because 
this protein is involved in gluconeogenesis and catalyzes the conversion of oxaloacetate to phosphoenolpyruvate in humans. This metabolite can be converted to pyruvate in the glycolytic pathway or to glucose in the gluconeogenesis pathway.

Another noteworthy finding in the present study is the up-regulation of chaperone protein dnaK (DnaK) after PyRSPy treatment (Table 1). DnaK is a chaperone protein in bacteria belonging to the heat shock $70 \mathrm{kDa}$ (Hsp70) chaperone protein family. When bound to ADP, DnaK binds to exposed hydrophobic residues of unfolded or partially mis-folded proteins, stabilizing them and giving them time to fold correctly [32]. DnaK is also involved in stabilizing precursor proteins, assisting the translocation of newly synthesized proteins, and protecting cells against cellular stress [33]. For many years Hsp70 in humans has been implied to play a neuroprotective role in some neuron degenerative diseases [34]. Hsp70 levels have been shown to decrease along with disease progression in the Huntington's diseased mouse brain, implicating its role in preventing the pathogenesis of the disease [35]. Furthermore, Hsp70 overexpression has been shown to reduce $\alpha$-Syn protein aggregate formation and toxicity in a mouse model of Parkinson's disease [36], and has caused mice to be more resistant to neurodegeneration following brain ischemia [37]. Hence, it is important to examine the effects of PySSPy and PyRSPy on the expressional changes of phosphoenol-pyruvate carboxykinase and DnaK, respectively, and the toxicity effects of these two compounds using a human cell line system to address their possible clinical importance.

\section{Conclusion}

We have shown for the first time through a proteomic approach that distamycin A-derived chiral compounds selectively regulate the expression of proteins at the molecular level. These compounds' non-cytotoxic nature are implicative of their potential in altering a particular cellular pathway without inducing cellular toxicity in host cells, hence offering the prospect of new drug development. The future studies are aimed at investigating whether these compounds exerted the same effects on human cells as on bacterial cells. Furthermore, the significance of these compounds in altering a particular cellular pathway and treating particular diseases remain to be determined.

\section{Methods}

\section{Chemicals and reagents}

Tris- $\mathrm{HCl}$, tris-base, phosphate buffer saline (PBS), 3-[(3cholamido-propyl)di-methylammonio]-1-propanesulfonate (CHAPS), iodoacetamide and acrylamide (40\%) were purchased from Amresco (OH, USA). Urea, glycerol, ammonium persulfate, and ammonium bicarbonate were purchased from Showa Chemicals Inc. Bradford protein assay kit and dithiothreitol (DTT) were obtained from GMbiolab Co. Ltd. Formic acid, trifluoroacetic acid and N,N,N',N'-Tetramethyl-1-,2-diamino-methane were purchased from Sigma-Aldrich, Co. Acetonitrile, thiourea and sodium dodecyl sulfate (SDS) were obtained from Merck. Pre stained protein marker and SimplyBlue SafeStain were purchased from Invitrogen (NY, USA), and $\alpha$-cyano-4-hydroxy-cinnamic acid from Tokyo Kasei Kogyo Co., Ltd (TCI). Immobilline Dry Strips ( $\mathrm{pH} 4-7,7 \mathrm{~cm}$, linear gradient) and immobilized $\mathrm{pH}$ gradient (IPG) buffer ( $\mathrm{pH} 4-7$ ) were purchased from GE healthcare.

\section{Cell culture and treatment}

A single colony of Escherichia coli $\mathrm{DH} 5 \alpha$ (E coli DH5 $\alpha)$ removed from agar containing Lysogeny broth (USB Products) was suspended in each of the $100 \mathrm{ml}$ of lysogeny broth media and grown for 24 hours by shaking at $160 \mathrm{rpm}$ at $30^{\circ} \mathrm{C}$. Subsequently, the cells were transferred into fresh lysogeny broth media $(0.03 \%(\mathrm{v} / \mathrm{v}))$ for a further 12 hours in the absence or presence of PySSPy, PyRSPy and 3A.

\section{Cell growth determination}

$E$ coli $\mathrm{DH} 5 \alpha$ were assessed for their cell growth by measuring their turbidity at $600 \mathrm{~nm}\left(\mathrm{OD}_{600}\right)$ using an ELISA plate reader (Thermo Multiskan Ascent). Triplicate samples from each treatment were obtained for the determination of mean values and standard deviations.

\section{Sample preparation for isoelectric focusing (IEF)}

Cells collected at the end of the incubation period were washed with phosphate buffer saline (PBS) and the final time with nanopure water at $9000 \mathrm{rpm}$ at $15^{\circ} \mathrm{C}$. The cell pellet was subsequently lysed by re-suspension in $0.5 \mathrm{ml}$ rehydration buffer (7 M urea, $2 \mathrm{M}$ thiourea and 4\% (w/v) CHAPS) and ultrasonication (Elmasonic E70H) for a total of 1 minute on ice. The supernatant, after centrifugation of the lysate at $12000 \mathrm{rpm}$ at $4^{\circ} \mathrm{C}$, was measured for protein content using the Bradford protein determination kit and stored at $-20^{\circ} \mathrm{C}$.

\section{Isoelectric focusing and second dimension SDS-PAGE gel electrophoresis}

Protein samples $(240 \mu \mathrm{g})$ were prepared by precipitation of the protein supernatant in $70 \%$ acetonitrile on ice for 20 minutes. The protein pellet was then dissolved in $120 \mu \mathrm{l}$ of rehydration buffer (7 M urea, $2 \mathrm{M}$ thiourea and $4 \%(\mathrm{w} / \mathrm{v})$ CHAPS), $50 \mathrm{mM}$ dithiothreitol (DTT) and 2\% IPG buffer (pH 4-7).

After rehydrating the 7-cm IPG strips ( $\mathrm{pH} 4-7)$ with the samples for 15 hours, isoelectric focusing (IEF) was conducted on these IPG strips by using a Protean IEF 
Cell (Bio-Rad). These samples required 100-24 000 voltage-hours for optimum focusing. After focusing, a conditioning step was conducted by treating the strips in equilibration buffer I ( $6 \mathrm{M}$ urea, $0.375 \mathrm{M}$ Tris- $\mathrm{HCl}$, $\mathrm{pH} 8.8,2 \%$ SDS (w/v), 20\% glycerol (w/v) and $130 \mathrm{mM}$ DTT) for 30 minutes and equilibration buffer II (6 M urea, $0.375 \mathrm{M}$ Tris- $\mathrm{HCl}, \mathrm{pH}$ 8.8, 2\% SDS (w/v), 20\% glycerol $(\mathrm{w} / \mathrm{v})$ and $135 \mathrm{mM}$ iodoacetamide) for another 30 minutes.

The second dimension (2D) SDS-PAGE gel was run by using $12 \%$ resolving gels composed of $12 \%$ acrylamide, $0.375 \mathrm{M}$ Tris- $\mathrm{HCl}, \mathrm{pH} 8.8,0.1 \%$ SDS, $0.1 \%$ ammonium persulfate, $\quad 0.08 \% \quad(\mathrm{v} / \mathrm{v}) \quad \mathrm{N}, \mathrm{N}, \mathrm{N}^{\prime}, \mathrm{N}^{\prime}-\mathrm{Tetramethyl-1-,2-}$ diamino-methane, and $0.5 \%$ stacking gel $(0.5 \%(\mathrm{w} / \mathrm{v})$ agarose and $0.002 \%(\mathrm{w} / \mathrm{v})$ bromophenol blue). The gels were stained with SimplyBlue SafeStain and directly scanned using a Microter 4100 scanner. The corresponding protein spots of interest from each different gel image were analyzed for their intensities using the Image J software (version 1.46), available on http:// rsbweb.nih.gov/ij/download.html. The protein intensities were normalized by dividing the intensities of the protein spots of interest by the intensity of a chosen protein spot in the same gel, whose intensity is considered not significantly changed across all the control and treated gels. The relative intensities of protein spots of interest were calculated by dividing the intensities of protein spots of interest by the intensities of the corresponding protein spots in the controls. The mean fold changes and the standard deviations in Table 1 were obtained from triplicate gel samples.

\section{In-gel digestion, MALDI-MS analyses, and protein identification}

The procedure for In-gel digestion was described by the Biological Mass Spectrometry Laboratory, the Ontario Wide Protein Identification Facility. Please refer to the website http://www.biochem.uwo.ca/wits/bmsl/index.html. Briefly, protein spots were excised and incubated with 40 $\mu \mathrm{l}$ of $50 \%$ acetonitrile in nanopure water for 15 minutes, followed by incubating the gel pieces with $100 \mathrm{mM}$ ammonium bicarbonate and acetonitrile in 1:1 ratio for 15 minutes. The gel pieces were subsequently dried in a speedvac and incubated with $40 \mu \mathrm{l}$ of $50 \mathrm{mM}$ DTT/100 $\mathrm{mM}$ ammonium bicarbonate at $56^{\circ} \mathrm{C}$ for 45 minutes. The gel pieces, after removal of the supernatant, were incubated with $40 \mu \mathrm{l}$ of $200 \mathrm{mM}$ iodoacetamide/100 $\mathrm{mM}$ ammonium bicarbonate at room temperature for $45 \mathrm{~min}$ in the dark. After discarding the supernatant at the end of the incubation, the gel pieces were treated with $40 \mu \mathrm{l}$ of $5 \mathrm{ng} / \mu \mathrm{l} \mathrm{se-}$ quencing grade modified trypsin (Promega, Madison, WI) in $25 \mathrm{mM}$ ammonium bicarbonate and the mixtures were incubated overnight at $37^{\circ} \mathrm{C}$. The supernatants from the trypsin-digested mixtures were collected in separate tubes, and peptides were extracted twice by treating the gel pieces with $30 \mu \mathrm{l}$ of acetonitrile/5\% formic acid in 1:1 ratio. The extracts were completely dried using a Speed Vac.

The dried peptides were dissolved in $5 \mu \mathrm{l}$ of $0.1 \%$ formic acid. One $\mu \mathrm{l}$ of peptide samples were mixed with $1 \mu \mathrm{l}$ of matrix solution (30 $\mathrm{mg} / \mathrm{ml} \alpha$-cyano-4- hydroxycinnamic in $70 \%$ acetonitrile/ $0.1 \%$ trifluoroacetic acid) onto a matrixassisted laser desorption/ionization (MALDI) plate, and allowed to air-dry. Spectra were acquired using Bruker Daltonics Autoflex III/Autoflex III TOF/TOF (serial number 238.120.00103). Peptide calibration for a mass range of $\mathrm{m} / \mathrm{z} 500$ to $\mathrm{m} / \mathrm{z} 2500$ was performed using $\alpha$-cyano-4hydroxycinnamic acid ( $\alpha-\mathrm{CHCA})$, angiotensin I, and adrenocorticotropic hormone (ACTH). The peak lists obtained were searched using Mascot search engine, and compared against non-redundant NCBI protein database. The following parameters were used: maximum allowed missed cleavages by trypsin was 1 ; fixed amino acid modification as carbamidomethyl; Escherichia coli was chosen for the taxonomy; the peptide tolerance for spectra obtained from MALDI was $\pm 0.5 \mathrm{Da}$. Only protein samples with MOWSE scores above the significant threshold level $(\mathrm{p} \leq 0.05)$ as determined by MASCOT were listed in Table 1 . The proteins identified were classified into different molecular functions, the elemental activities of a gene product at molecular level, using the Uni Protein Knowledgebase (UniProtKB) database available on http://www.uniprot.org/.

\section{Statistical analysis}

Data was plotted and statistically analyzed using the Prism software program (GraphPad Software, USA). Significance was confirmed by a one-way analysis of variance [8] and Tukey's multiple comparison test. Significance levels are indicated in the following manner: ${ }^{*} \mathrm{p} \leq 0.05$; ${ }^{* *} \mathrm{p} \leq 0.01$; $* * 0.001$. The means and standard deviations shown within each experiment were calculated from triplicate samples.

\section{Additional files}

\footnotetext{
Additional file 1: $E$. coli DH5a cell growth after treatment with the distamycin A derivative PySSPy. E. coli DH5a in LB broth were treated with 0 (dark square), 50 (inverted white triangle), 100 (white triangle), 150 (white circle), 200 (white diamond), 300 (white square) $\mu \mathrm{M}$ PySSPy at $37^{\circ} \mathrm{C}$ for 15 hours. Cell density was determined at time intervals through OD 600 measurement. Each data point was subtracted from blank controls. Each data point was the mean result of triplicate values. Standard deviations were calculated for each data point and presented as error bars.

Additional file 2: The proteomic gel images of $E$. coil DH5a control. E. coil DH5a were treated in the absence of $300 \mu \mathrm{M}$ PySSPy. $300 \mu \mathrm{M}$ PyRSPy or $300 \mu \mathrm{M} 3 \mathrm{~A}$ at $37^{\circ} \mathrm{C}$ for 10 hours, followed by 2D gel electrophoresis. The gels were visualized using commercial SimplyBlue SafeStain. The gels images A), B) and C) were obtained from three independent experiments.

Additional file 3: The proteomic gel images of E. coil DH5a treated with PySSPy. E coli DH5a were treated with $300 \mu \mathrm{M}$ PySSPy at $37^{\circ} \mathrm{C}$ for 10 hours, followed by 2D gel electrophoresis. The gels were visualized
} 
using commercial SimplyBlue SafeStain. The gels images A), B) and C) were obtained from three independent experiments.

Additional file 4: The proteomic gel images of E. coil DH5a treated with PyRSPy. E. coli DH5a were treated with $300 \mu \mathrm{M}$ PyRSPy at $37^{\circ} \mathrm{C}$ for 10 hours, followed by 2D gel electrophoresis. The gels were visualized using commercial SimplyBlue SafeStain. The gels images A), B) and C) were obtained from three independent experiments.

Additional file 5: The proteomic gel images of E. coil D115u treated with $3 \mathrm{~A}$. E. coil DH5a were treated with $300 \mu \mathrm{M} 3 \mathrm{~A}$ at $37^{\circ} \mathrm{C}$ for 10 hours, followed by $2 \mathrm{D}$ gel electrophoresis. The gels were visualized using commercial SimplyBlue SafeStain. The gels images A), B) and C) were obtained from three independent experiments.

\section{Abbreviations}

2-DE: Two-dimensional gel electrophoresis; CHAPS: 3-[(3-cholamido-propyl) dimethyl-ammonio]-1-propanesulfonate; DTT: Dithiothreitol; E coli: Escherichia coli; Hsp: Heat shock; IPG: Immobilized pH gradient; IEF: Isoelectric focusing; LB: Lysogeny broth; MALDI-TOF: Matrix-assisted laser desorption/ionizationtime of flight; PAGE: Polyacrylamide gel electrophoresis; PBS: Phosphate buffer saline; SDS: Sodium dodecyl sulfate.

\section{Competing interests}

The authors declare that they have no competing interests.

\section{Authors' contributions}

YTY, CWO and JYJ designed the study. YTY and CYL carried out the experiments. CYL designed and synthesized the compounds. YTY wrote the manuscript, and CWO and JYJ corrected the manuscript. All authors read and approved the final manuscript

\section{Acknowledgements}

This work was supported by the National Science Council, Taiwan, R.O.C (099-2811-M-110 011 and 100-2811-M-110-023). The authors thank Prof. Jentaie Shiea of the Chemistry Department, National Sun Yat-sen University and his laboratory members for their kind assistance in MALDI/MS analyses and in gel digestion execution. The authors also thank Prof. Jingyueh Jeng's laboratory students for their assistance in 2D gel electrophoresis execution.

Received: 7 January 2013 Accepted: 13 May 2013

Published: 23 May 2013

\section{References}

1. Turner PR, Denny WA: The genome as a drug target: sequence specific minor groove binding ligands. Curr Drug Targets 2000, 1:1-14.

2. Neidle S: DNA minor-groove recognition by small molecules. Nat Prod Rep 2001, 18:291-309.

3. Hurley LH (Ed): Sequence specificity of drugs that interact with DNA in the minor groove. In Advances in DNA Sequence-Specific Agents 1992, 1:217-360.

4. Hurley LH, Chaires JB (Eds): Sequence Specificity of DNA Interactive Drugs. In Advances in DNA Sequence Specific Agents. 1996, 2:141-256.

5. Propst CL, Perun TJE: Nucleic Acid Targeted Drug Design. New York, NY: Marcel Dekker; 1992.

6. Lang D, Stamminger T: Minor groove contacts are essential for an interaction of the human cytomegalovirus IE2 protein with its DNA target. Nucleic Acids Res 1994, 22:3331-3338.

7. Reddy BS, Sondhi SM, Lown JW: Synthetic DNA minor groove-binding drugs. Pharmacol Ther 1999, 84:1-111.

8. Valíka M, Malinab J, Paliveca L, Foltýnováa J, Tkadlecováa M, Urbanovác M, Brabecb V, Krála V: Tröger's base scaffold in racemic and chiral fashion as a spacer for bisdistamycin formation. Synthesis and DNA binding study 2006, 62:8591-8600.

9. Herman DM, Baird EE, Dervan PB: Stereochemical Control of the DNA Binding Affinity, Sequence Specificity, and Orientation Preference of Chiral Hairpin Polyamides in the Minor Groove. J Am Chem Soc 1998, 120:1382-1391.

10. Lin C-Y, Yang Y-T, Ong C-W: Synthesis of Chiral Pyrrolidine Isostere Inserted into Pyrrole Polyamide Skeleton. J Chin Chem Soc 2012, 59:436-442.

11. Wall DP, Tonellato PJ: The future of genomics in pathology. F1000 Med Rep 2012. in press.
12. Osborne JD, Flatow J, Holko M, Lin SM, Kibbe WA, Zhu LJ, Danila MI, Feng G, Chisholm RL: Annotating the human genome with Disease Ontology. BMC Genomics 2009, 10:S6

13. Sun G: Application of DNA microarrays in the study of human obesity and type 2 diabetes. OMICS 2007, 11:25-40.

14. Kurella M, Hsiao LL, Yoshida T, Randall JD, Chow G, Sarang SS, Jensen RV, Gullans SR: DNA microarray analysis of complex biologic processes. J Am Soc Nephrol 2001, 12:1072-1078.

15. Schnabel RB, Baccarelli A, Lin H, Ellinor PT, Benjamin EJ: Next steps in cardiovascular disease genomic research-sequencing, epigenetics, and transcriptomics. Clin Chem 2012, 58:113-126.

16. Rogers S, Girolami M, Kolch W, Waters KM, Liu T, Thrall B, Wiley HS: Investigating the correspondence between transcriptomic and proteomic expression profiles using coupled cluster models. Bioinformatics 2008, 24:2894-2900.

17. Dhingra V, Gupta M, Andacht T, Fu ZF: New frontiers in proteomics research: a perspective. Int J Pharm 2005, 299:1-18.

18. Greenbaum D, Colangelo C, Williams K, Gerstein M: Comparing protein abundance and mRNA expression levels on a genomic scale. Genome Biol 2003, 4:117.

19. Guo Y, Xiao P, Lei S, Deng F, Xiao GG, Liu Y, Chen X, Li L, Wu S, Chen Y, Jiang $H$, Tan L, Xie J, Zhu X, Liang S, Deng H: How is mRNA expression predictive for protein expression? A correlation study on human circulating monocytes. Acta Biochim Biophys Sin (Shanghai) 2008, 40:426-436.

20. Blattner FR, Plunkett G, Bloch CA, Perna NT, Burland V, Riley M, Collado-Vides J, Glasner JD, Rode CK, Mayhew GF, Gregor J, Davis NW, Kirkpatrick HA, Goeden MA, Rose DJ, Mau B, Shao Y: The complete genome sequence of Escherichia coli K-12. Science 1997, 277:1453-1462.

21. Butland G, Peregrín-Alvarez JM, Li J, Yang W, Yang X, Canadien V, Starostine A, Richards D, Beattie B, Krogan N, Davey M, Parkinson J, Greenblatt J, Emili A: Interaction network containing conserved and essential protein complexes in Escherichia coli. Nature 2005, 433:531-537.

22. Pandey A, Mann M: Proteomics to study genes and genomes. Nature 2000, 405:837-846.

23. Lockhart DJ, Winzeler EA: Genomics, gene expression and DNA arrays. Nature 2000, 405:827-836.

24. Nielsen J, Olsson L: An expanded role for microbial physiology in metabolic engineering and functional genomics: moving towards systems biology. FEMS Yeast Res 2002, 2:175-181.

25. Yoon SH, Han MJ, Lee SY, Jeong KJ, Yoo JS: Combined transcriptome and proteome analysis of Escherichia coli during high cell density culture. Biotechnol Bioeng 2003, 81:753-767.

26. Han MJ, Lee SY: The Escherichia coli proteome: past, present, and future prospects. Microbiol Mol Biol Rev 2006, 70:362-439.

27. Lee PS, Lee KH: Escherichia coli-a model system that benefits from and contributes to the evolution of proteomics. Biotechnol Bioeng 2003, 84:801-814

28. $F u$ W, Yu Y, Xu L: Identification of temporal differentially expressed protein responses to microcystin in human amniotic epithelial cells. Chem Res Toxicol 2009, 22:41-51.

29. Jiang $Y L$, Ning $Y, M a X L$, Liu $Y Y$, Wang $Y$, Zhang Z, Shan CX, Xu YD, Yin LM, Yang YQ: Alteration of the proteome profile of the pancreas in diabetic rats induced by streptozotocin. Int J Mol Med 2011, 28:153-160.

30. Sala GL, Ronzitti G, Sasaki M, Fuwa H, Yasumoto T, Bigiani A, Rossini GP. Proteomic analysis reveals multiple patterns of response in cells exposed to a toxin mixture. Chem Res Toxicol 2009, 22:1077-1085.

31. Beal DR, Titball RW, Lindsay CD: The development of tolerance to Clostridium perfringens type D epsilon-toxin in MDCK and G-402 cells. Hum Exp Toxicol 2003, 22:593-605.

32. Bukau B, Horwich AL: The Hsp70 and Hsp60 chaperone machines. Cell 1998, 92:351-366.

33. Boshoff A, Nicoll WS, Hennessy F, Ludewig MH, Daniel S, Modisakeng KW, Shonhai A, McNamara C, Bradley G, Blatch GL: Molecular chaperones in biology, medicine and protein biotechnology. South African J Sci 2004, 100:665-677.

34. Turturici G, Sconzo G, Geraci F: Hsp70 and its molecular role in nervous system diseases. Biochem Res Int 2011, 2011:1-18.

35. Hay DG, Sathasivam K, Tobaben S, Stahl B, Marber M, Mestril R, Mahal A, Smith DL, Woodman B, Bates GP: Progressive decrease in chaperone protein levels in a mouse model of Huntington's disease and induction 
of stress proteins as a therapeutic approach. Hum Mol Genet 2004 13:1389-1405.

36. Klucken J, Shin Y, Masliah E, Hyman BT, McLean PJ: Hsp70 Reduces alpha-Synuclein Aggregation and Toxicity. J Biol Chem 2004, 279:25497-25502.

37. Plumier JC, Krueger AM, Currie RW, Kontoyiannis D, Kollias G, Pagoulatos GN: Transgenic mice expressing the human inducible Hsp70 have hippocampal neurons resistant to ischemic injury. Cell Stress Chaperones 1997, 2:162-167.

doi:10.1186/1477-5956-11-23

Cite this article as: Yang et al: Impact of pyrrolidine-bispyrrole DNA minor groove binding agents and chirality on global proteomic profile in Escherichia Coli. Proteome Science 2013 11:23.

\section{Submit your next manuscript to BioMed Central and take full advantage of:}

- Convenient online submission

- Thorough peer review

- No space constraints or color figure charges

- Immediate publication on acceptance

- Inclusion in PubMed, CAS, Scopus and Google Scholar

- Research which is freely available for redistribution 